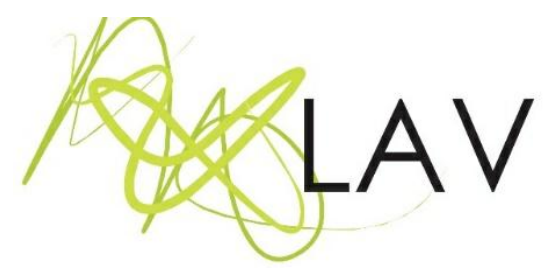

\title{
Instalações artísticas: observar, criar e transformar
}

Art installations: observing, creating and transforming

\author{
Ítalo Butzke \\ NEI Paulistinha - Unifesp \\ Daves Otani \\ Escola Superior de Artes Célia Helena
}

\section{Resumo}

Este artigo tem o intuito de cunhar os conceitos de instalação direta e indireta na educação infantil. No âmbito geral, o texto problematiza os espaços comuns escolares, além de elaborar reflexões acerca da contribuição das instalações artísticas no desenvolvimento infantil. Por fim, é feito um estudo de caso, a fim de apontar a presença das instalações diretas e indiretas no ambiente escolar, bem como caracterizá-las. Com isso, espera-se que a explanação dessas ideias sirva como convite para refletir sobre a criação desses ambientes e a sua importância no repertório das crianças.

Palavras-chave: Instalação direta, Instalação indireta, Educação infantil, Processo criativo.

\begin{abstract}
This article intends to coin the concepts of direct and indirect installation in early childhood education. In general, the text problematizes school common spaces, in addition to elaborating reflections about the contribution of art installations during child development. Finally, a case study is carried out, in order to point out the presence of direct and indirect facilities in the school environment, as well as to characterize them. Thus, it is hoped that the explanation of these ideas will serve as an invitation to reflect on the creation of these environments and their importance in the children's repertoire.
\end{abstract}

Keywords: Direct Installation, Indirect Installation, Early Childhood Education, Creative Process.

Enviado em: 25/04/21 - Aprovado em: 02/09/21 


\section{Introdução}

As Instalações artísticas surgem com a proposta de dialogar com os espaços, projetos e linguagens na educação infantil, registrando o processo criativo com turmas de crianças em seu percurso investigativo.

Na criação da fala e da linguagem, brincando com essa maravilhosa faculdade de designar, é como se o espírito estivesse constantemente saltando entre a matéria e as coisas pensadas. Por detrás de toda expressão abstrata se oculta uma metáfora, e toda metáfora é jogo de palavras. Assim, ao dar expressão à vida, o homem cria um outro mundo, um mundo poético, ao lado da natureza (HUIZINGA, 2007, p. 07).

Compreendemos que as crianças se expressam por meio de múltiplas linguagens e, através delas, se relacionam com o mundo físico, social, artístico e cultural. Acreditando na potência da criança e em uma educação horizontal e crítica, em que a construção dos saberes se dá de forma coletiva e colaborativa, respeitando as subjetividades, a história e cultura de cada sujeito, entendemos ser necessário caminharmos juntos para preparar um terreiro que faça sentido e carregue significados. Chamaremos de terreiro a transformação do espaço em ambiente. Conforme o dicionário Michaelis (2020, s/p.), terreiro é "terreno que pode ser cultivado [...] onde se realizam folguedos, cantos e outras festas populares".

É no processo criativo brincante que esse terreiro pode ser construído, a partir do brincar que as descobertas surgem e a criança desvela o mundo, interage com novos parceiros e se expressa. Um ambiente que possibilita interações é fundamental, e é nesse cenário que ocorre o desenvolvimento infantil. A autora Teresa Cristina Rego (1995, p. 58) relembra que "Vygotsky chama a atenção para a ação recíproca existente entre o organismo e o meio e atribui especial importância ao fator humano presente no ambiente".

Paralelamente, ainda na perspectiva de Vygotsky, Rego complementa que:

O desenvolvimento está intimamente relacionado ao contexto sociocultural em que a pessoa se insere e se processa de forma dinâmica (e dialética) através de rupturas e desequilíbrios provocadores de contínuas reorganizações por parte do indivíduo (REGO, 1995, p. 58).

Portanto, pensamos que a escola de educação infantil deve ser um enorme terreiro de jogos e brincadeiras, no qual as crianças se expressam e constroem suas subjetividades. Um ambiente que potencializa a imaginação e a criação, e que possibilita descobertas e interações, criando cultura. Nessas perspectivas, acreditamos ainda que as instalações 
artísticas são um meio para o desenvolvimento das múltiplas linguagens. Conforme Susana Rangel Vieira da Cunha,

As crianças pequenas iniciam o conhecimento sobre o mundo através dos cinco sentidos (visão, tato, olfato, audição, degustação) do movimento, da curiosidade em relação ao que está em sua volta, da repetição, da imitação, da brincadeira e do jogo simbólico. No que diz respeito às linguagens expressivas, estes são os fatores fundamentais para que elas se desenvolvam plenamente (CUNHA, 1999, p. 10).

Portanto, o nosso intuito é cunhar os conceitos de instalação artística direta e instalação artística indireta, além de analisarmos como cada uma delas estão presentes nos projetos escolares. O estudo de caso em questão será realizado a partir dos Projetos da aranha e da tartaruga, desenvolvidos em 2019 com a turma Mundo Encantado, composto por crianças de 3 anos de idade, do NEI - Paulistinha/Unifesp ${ }^{1}$.

\section{As instalações artísticas²}

[...] os artistas modernos foram admiradores da arte infantil pela sua simplicidade e liberdade de expressão, sem preocupação com a representação do real, mas pela expressão do seu universo simbólico, marcado por suas experiências no fazer e no observar o ambiente natural e cultural (IAVELBERG, 2017, p. 36).

Quando Duchamp, no início do século XX, desloca um objeto usual e leva-o para o museu, acontece um processo de ressignificação e abre-se as portas para um novo fazer artístico, bem como para a Arte em si. Uma de suas obras mais icónicas é $A$ fonte (1917), na qual o artista deslocou um urinol de porcelana para o museu. O público foi convidado a refletir sobre o que seria Arte, bem como observar os detalhes que passavam despercebidos e ganharam luz, assim como outras partes e funções que não foram exploradas ou descobertas anteriormente, também receberam significados. Dessa forma, saberes já adquiridos puderam ser ressignificados.

\footnotetext{
1 O Núcleo de Educação Infantil Paulistinha é a creche da Universidade Federal de São Paulo. Fundada em 1971, era conhecida como Comunidade Infantil (CI), ou mais popularmente 'Paulistão', um local adaptado para as/os filhas/os de funcionárias/os e estudantes da Escola Paulista de Enfermagem (EPE). Hoje, as vagas são destinadas para a comunidade da Unifesp e externa. Apesar de estar ligada ao Governo Federal e à Secretaria de Educação do Estado de São Paulo, não recebe o suporte destas, tendo uma gestão compartilhada entre a SPDM - Associação do desenvolvimento da medicina, Hospital São Paulo e a reitoria da Unifesp. As pesquisas sobre as práticas da educação infantil são fragilizadas, até mesmo porque, quase $80 \%$ das/os funcionárias/os são contratadas/os no regime CLT.

2 É uma manifestação artística contemporânea, que estuda os objetos e elementos nos espaços, onde, na maioria das vezes, buscam a interação do público.
} 
Dessa maneira, ao longo dos anos, as instalações obtiveram novos sentidos e os artistas passaram a explorar diversos elementos, espaços, técnicas e tecnologias, como explica Milton Sogabe (2008, p. 02): "nesse processo observamos que o espaço das instalações vem se modificando, refletindo o desenvolvimento tecnológico, as discussões artísticas de cada época e até revelando conceitos científicos de espaço".

As mutações das instalações transcendem o espaço físico e passam a ganhar o ciberespaço, mas mesmo com todas essas transformações ainda podemos defini-las de duas formas: 1) como a interação do sujeito com a obra, e 2) como a obra explora o espaço em um tempo determinado. Em sua tese de doutorado, Luciana Bosco e Silva (2012, p. 11-12) vê que "o espaço e tempo da Instalação vem de uma experiência pessoal, de uma curiosidade e de uma necessidade de compreender as relações entre a ocupação espacial e o tempo".

A relação do sujeito com o meio através da exploração da arte contemporânea, sua fluidez e efemeridade, ao mesmo tempo que respeita a subjetividade das experiências, nos faz questionar o porquê de a arte contemporânea estar tão distante do cotidiano escolar. Para Cunha (2017, p. 15) "a grande 'novidade' da arte contemporânea é, então, transformar os sujeitos, antes espectadores passivos, em sujeitos criativos, ativos, que participam e expandem seus pensamentos e imaginação a partir das obras".

Nessa perspectiva, é contraditório pensar no caminho que a educação rumou, visto que a maioria dos trabalhos das crianças ainda são feitos a partir de um suporte em um riscante, expostos em painéis fixos, comumente fora dos olhares das crianças devido à altura, privilegiando apenas os adultos. Compartilho do pensamento das autoras Silveira e Vieira, de que na educação infantil

Costuma-se oferecer sempre as mesmas folhas, o mesmo lápis e as crianças replicam, a cada vez, os mesmos desenhos. Entendemos que há a necessidade de o professor propiciar aos alunos desafios em suas propostas, para que a criança experimente novas formas de expressão, indo além daquilo que já sabe fazer com os materiais (SILVEIRA; VIEIRA, 2017, p. 104).

Em uma abordagem pessoal, confessamos que, ao caminharmos no meio urbano, por vezes nos sentimos circunscritos a uma prática bancária e autoritária. Entre becos, ruas e avenidas, sempre somos arremessados a um jogo de percurso, com a trajetória já pré-determinada, em que seguimos entre os obstáculos fixos, passagens estáveis, imutáveis e concretas, oriundos do concreto cinza. 
Essa nossa estranheza ocorre também nos centros das grandes cidades, pois está intimamente relacionada às paredes físicas que crescem de forma vertical, sempre impossibilitando o ir e o vir, em prol da materialização dos ambientes privados. Não é possível observar o horizonte ou o céu.

Quem mora na cidade grande, nessa profusão de luz e de barulho, não olha mais para o céu. Se olhar, só enxerga o topo do edifício. O homem moderno, urbano, da época industrial desaprendeu a viver no ciclo da natureza. Se estiver com frio, liga o aquecedor. Se for calor, o ar condicionado do carro ou do escritório (RIOS, 2014, p. $800)$.

Em geral, transformamos nossos espaços em ambientes que não nos permitem viver ou conviver plenamente, nossa cidade é constituída de casas e prédios privados. São raros os lugares para explorar, com exceção às permissões ou convites cedidos por proprietários dessas áreas. São inquietações dessa natureza que nos levam à busca de uma educação transformadora, permeada por mudanças e reflexões acerca do nosso cotidiano, que forme sujeitos críticos ao mundo em que vivemos.

Dessa forma, acreditamos que espaços estáticos não convidam para novas descobertas, dizemos isso por observar que inúmeras escolas têm seus parques, salas de aula e corredores distantes de intervenções. As mudanças só acontecem em datas comemorativas ou, em alguns casos, quando surgem brinquedos e/ou objetos novos, normalmente de origem industrial ${ }^{3}$. Nessa perspectiva, partilhamos do pensamento de Cunha (1999, p. 20), de que "criar espaços diferenciados e convidativos à descobertas é uma modalidade de possibilitar às crianças o conhecimento espacial", além de promover desafios amplos para os corpos, ao provocar esteticamente e/ou sensorialmente ambientes que dialoguem com os temas de investigação destes.

A obra se apropria, portanto, do espaço, através de experimentações artísticas e é deste espaço, onde esta efetivamente se instala, que a Instalação emerge, trazendo em si conceitos que abrangem uma pluralidade de recursos materiais e variadas formas de associações e metáforas, as quais permitem a experiência única do espaço (SILVA, 2012, p. 13).

O espaço possibilita a exploração de diversos elementos, como vento, luz, som, objetos, entre outras alternativas. Estes podem ser explorados separadamente, focando somente no elemento em si e em suas possibilidades, por exemplo, a luz e suas intensidades, cores, reflexos e sombras. Vale ressaltar que, ao se tratar da educação

\footnotetext{
${ }^{3}$ Quando citamos o termo brinquedos industriais, referimos-nos aos de cultura da massa, onde sua produção é em escala industrial.
}

Revista Digital do LAV - Santa Maria - vol. 14, n. 3, p. 48 - 66 - set./dez. 2021 ISSN 1983 - 7348 
infantil, essas questões devem ser avaliadas conforme o tema de investigação da turma e a faixa etária das crianças. É importante ainda verificar se o momento é oportuno para inserir novos elementos, podendo interligar ou divergir. Além disso, inserir ou retirar um elemento pode potencializar o terreiro para novas brincadeiras, deixando-o lúdico para novas leituras e descobertas.

[...] uma Instalação determina um universo próprio que para ser apreciado, necessita ser vivenciado. Para ter a fruição plena de uma Instalação se faz mandatório interagir com ela, penetrá-la quando possível, se submeter as suas manipulações sensoriais sem preconceitos e sem receios, só assim a fruição da mesma é possível de forma absoluta (SILVA, 2012, p. 14).

Acreditamos que este seja o maior potencializador das instalações artísticas, proporcionar um ambiente que possibilite leituras, que contribua para que as crianças possam decodificar algumas linguagens que ainda não puderam experimentar, em um ambiente que respeite sua subjetividade e seu tempo.

Ao mesmo tempo que a criança descobre o mundo exterior e nele exerce uma ação, sua imaginação se desenvolve. Pelo imaginário, encontra possibilidades de vinculação e conexões com o mundo, balizando o itinerário interior. Pela atividade, a criança se confronta com os outros, com o real, ao fazer descobertas, ao sentir alegria e dores, ao viver apegos e conflitos. Passa a conhecer suas possibilidades de ação e também seus limites (RICHTER, 1999, p. 41).

Por isso, modificar os espaços escolares é levar às crianças uma forma de mudança no mundo, visto que, como já citado, o ambiente escolar costuma ser estático. Portanto, as instalações nas escolas trazem à tona uma pedagogia problematizadora.

[...] a prática bancária, como enfatizamos, implica numa espécie de anestesia, inibindo o poder criador dos educandos, a educação problematizadora, de caráter autenticamente reflexivo, implica num constante ato de desvelamento da realidade. A primeira pretende manter a imersão; a segunda, pelo contrário, busca a emersão das consciências, de que resulte sua inserção crítica na realidade (FREIRE, 1974, p. 80).

As instalações no ambiente escolar potencializam a práxis. Conforme Fortuna (2015, p. 65) traz sobre a pedagogia Freiriana, "teoria e prática são inseparáveis tornandose, por meio de sua relação, práxis autêntica, que possibilita aos sujeitos reflexão sobre a ação, proporcionando educação para a liberdade". Essa reflexão sobre a ação versus reflexão (fruição) versus ação torna-se diferente quando as crianças vão à uma exposição 
de artes que tenha instalações, pois, neste momento, a participação delas é a interação com o espaço/objeto/elemento, logo, seria a fruição da obra de arte apresentada.

A seguir, trazemos uma reflexão sobre dois conceitos de instalações no ambiente escolar, a direta, onde as crianças participam de todo o processo criativo, e a indireta, quando a instalação é pensada pelas/os educandas/os para potencializar os projetos que estão em andamento. Antes de tudo, vale ressaltar que tanto a instalação direta como a indireta partem da escuta das crianças, para isso, é necessário estar com os sentidos apurados, porque esse diálogo, muitas vezes, não ocorre verbalmente. As crianças se comunicam a partir de uma narrativa poética, com fios estruturais sutis e transparentes, em que é preciso sentir as vibrações melódicas, como se cada educando fosse um instrumento diferente do outro. As rodas de conversas são o momento de afinar os instrumentos, assim, ao longo do dia ocorre a sinfonia, sendo o educador o maestro dessa orquestra.

O maestro, por sua vez, não tem a função de saber tocar os instrumentos que compõem a orquestra, e sim de conhecê-los perfeitamente, a fim de preparar uma atmosfera que proporcione o autoconhecimento e a potencialidade de cada instrumento, observando os solos melódicos no cotidiano escolar. Com isso, o indivíduo se reconhece para trabalhar no coletivo.

Para elaborar um projeto de trabalho é preciso realmente conhecer o grupo de crianças e para isso é necessário estabelecer uma escuta e uma observação atenta, a fim de fazer uma interlocução com o que as crianças nos dizem e nos mostram no cotidiano do grupo. Esse olhar a criança é realmente o ponto de partida, pois só assim podemos traçar objetivos claros respeitando não só sua faixa etária como também o que Ihe é significativo e o que é importante para a sua interação com o mundo (MAGDALENO, 2000, p. 87).

Após os primeiros ensaios, o grupo caminha em busca da definição de uma música, que representa o tema a ser trabalhado, passando em seguida por um processo de vivências e experimentos que possibilitem a ampliação do repertório dos participantes. Após essa definição e as pesquisas iniciais, os músicos e o maestro retomam os estudos acerca do trabalho. Essa alusão aqui descrita remete ao projeto de investigação da turma, já que eles

[...] deverão ser pensados através de um conjunto de atividades interligadas e sequenciais. É importante que o educador organize seu trabalho como uma novela, onde a história vai se desenvolvendo gradativamente [...] (CUNHA, 1999, p. 33). 
Dessa forma, o processo pode durar o semestre ou até mesmo o ano letivo, dependendo do caminhar das pesquisas.

\section{Instalação indireta}

A instalação indireta ocorre quando se observa que duas ou mais turmas estão investigando o mesmo tema, temas próximos ou até mesmo quando os projetos conversam entre si. Com isso, realizamos uma instalação que dialogue com esses projetos, potencializando novas descobertas e/ou releituras, a fim de apresentá-los a novas linguagens.

A arte contemporânea, entre outras proposições, incita o deslocamento da posição de autoria individual para a autoria coletiva, considerando o observador como um sujeito que também compõe a obra. As crianças experimentam e vivem os processos de recriação por meio de ações simbólicas e concretas, percebem-se outras em suas relações com o mundo e com seus pares (BORGES, 2017, p. 65).

É importante salientar que os elementos que irão compor a instalação e o lugar que ela será montada são definidos pela equipe docente, aproximando o tema investigado com o investigador, conforme propõe Rego, partindo dos estudos de Vygotsky, em que o educador cria a zona de desenvolvimento proximal, para que a criação, assim, alcance o nível de desenvolvimento real.

O aprendizado é o responsável por criar a zona de desenvolvimento proximal, na medida em que, em interação com outras pessoas, a criança é capaz de colocar em movimento vários processos de desenvolvimento que, sem a ajuda externa, seriam impossíveis de ocorrer. Esses processos se internalizam e passam a fazer parte das aquisições do seu desenvolvimento individual (REGO, 1995, p. 74).

O diálogo do sujeito com a obra se torna uma experiência subjetiva, pois

[...] quando falamos de Instalação o espectador/observador já não se coloca em uma posição contemplativa e/ou passiva, o observador se torna espectador/observador/fruidor/experimentador e a obra seu objeto não mais de contemplação, mas de interação (SILVA, 2012, p. 16).

É nesta práxis que as instalações vão se definindo, entre interação e reflexão, afinando cada instrumento em seu tom e tempo, compondo horizontalmente o desfecho da orquestra. A instalação indireta cria um ambiente lúdico, no qual as crianças têm a 
experiência de atravessá-lo, ao mesmo tempo que são afetadas pelos elementos que a compõem, podendo surgir novos signos e significados sobre o tema que está sendo estudado.

A criança utiliza os recursos simbólicos dos meios artísticos para construir representações significativas que só a arte permite, nos seus limites e nas suas possibilidades de objetivar o subjetivo, através da ação gestual e simbólica sobre a matéria. Transformar ludicamente a realidade material proporciona às crianças um canal exclusivo para abordar e elaborar significados importantes e complexos que o verbal não alcança nesta idade (RICHTER, 1999, p. 52).

Vemos, então, que é na base lúdico brincante que o objeto de estudo e o ensino aprendizagem torna-se significativo. Para tal, apoiamo-nos em eixos estruturantes da Base Nacional Comum Curricular para Educação Infantil, que alega:

A interação durante o brincar caracteriza o cotidiano da infância, trazendo consigo muitas aprendizagens e potenciais para 0 desenvolvimento integral das crianças. Ao observar as interações e a brincadeira entre as crianças e delas com os adultos, é possível identificar, por exemplo, a expressão dos afetos, a mediação das frustrações, a resolução de conflitos e a regulação das emoções (BRASIL, 2018, s/p.).

A instalação indireta é um ambiente potencializador e criador, ocorrendo constantemente pela mutação a partir das interações, nutrindo brincadeiras e jogos, vivenciando experiências com objetos, sujeitos e o mundo, contribuindo para o desenvolvimento das múltiplas linguagens. Conforme as Diretrizes Curriculares Nacionais para a Educação Infantil, as escolas devem garantir experiências que "[...] favoreçam a imersão das crianças nas diferentes linguagens e o progressivo domínio por elas de vários gêneros e formas de expressão: gestual, verbal, plástica, dramática e musical" (BRASIL, 2010, p. 25).

\section{Instalação direta}

Tanto a instalação direta quanto a instalação indireta proporcionam uma nova forma de experienciar o mundo, no entanto, a direta é realizada pontualmente com um projeto de investigação, somente com uma turma. Após a escolha da música - definição do tema do projeto investigativo, o maestro e a orquestra fazem os primeiros ensaios, e então é a hora de decidir qual cenário a apresentação usará. Com essa analogia, brincamos na forma 
como vemos o dia-a-dia da escola e as etapas do processo criativo que vão se construindo e se descobrindo.

O educador problematizador refaz, constantemente, seu ato cognoscente, na cognoscibilidade dos educandos. Estes, em lugar de serem recipientes dóceis de depósitos, são agora investigadores críticos, em diálogo com o educador, investigador crítico, também (FREIRE, 1974, p. 80).

Claro que, ao final do processo, não ocorre uma apresentação do projeto que foi desenvolvido, por isso seguimos essa linha de raciocínio, apoiando-nos na alegação de Vygotsky de que o processo está na criação e imaginação da criança, e não no resultado final, ele diz que tudo "[...] deve ser feito pelas mãos e pela imaginação das crianças, e somente assim a criação dramática adquire para elas todo o significado e toda a força" (VYGOTSKY, 2009, p. 101). Diferente da instalação indireta, o processo é escolhido e composto junto com as crianças, pois acreditamos que nas escolhas dos elementos, objetos e no processo de construção e criação podem ocorrer descobertas significativas, por vezes mais do que a instalação final.

O importante é oportunizar às crianças novas experiências e invenções com os materiais, sem delimitar em desenho, pintura, escultura, mas trabalhando com a hibridização das linguagens [...], criando instalações de aromas, sons, sensações, extrapolando qualquer referência que temos sob a denominação de 'artes visuais', indo além das linguagens tradicionais da arte (CUNHA, 2017, p. 18).

Elaborar uma instalação com as crianças fortalece o desenvolvimento do trabalho coletivo. Nas rodas de conversas, definimos as etapas do processo, assim como os materiais que utilizaremos. Abrem-se novos leques de investigações e descobertas com as experimentações dos materiais expressivos, como tintas, terra, tecidos e papéis, do espaço e sua transformação gradual.

As instalações artísticas não partem do princípio de objeto artístico imutável, ao contrário, é mutável porque representa um ambiente em que as crianças são precursoras de brincadeiras e descobertas, possibilitando a criação de personagens e ações a partir de sua imaginação, contribuindo para materializá-los nesse ambiente que se constrói.

Ou seja, a instalação direta é caracterizada pela construção a partir da escuta e da participação dos educandos, descobrindo e aprendendo juntos novas possibilidades plásticas, de dimensões e construções, e interagindo em todo o processo com os objetos e elementos. Já na instalação indireta, há escuta para que o projeto de investigação seja definido, mas a montagem é pensada e realizada somente pelos educadores, de forma que 
dialogue com os projetos em andamento ou que estejam por iniciar, com o intuito de provocar e repertoriar nas investigações e pesquisas. Partindo destes conceitos, o estudo de caso se propõe a analisar a presença da instalação artística direta e indireta nos projetos escolares já citados anteriormente.

\section{Estudo de caso}

No começo do ano letivo, as turmas dos infantis no NEI-Paulistinha buscam um nome, afinando um consenso acerca da definição do objeto de pesquisa daquele momento. No caso deste estudo de caso foi escolhido o Maternal II, em que o processo de escolha ocorreu a partir de uma roda de conversa. Dessa forma, surgiram diversos personagens encantados, e por isso, após votação, o nome definido foi Mundo Encantado.

Muitas vezes o projeto do semestre não surge de imediato ou a partir do nome da turma, e sim por acaso, como aconteceu nesta situação. Essa turma estava precisando de suporte para expor os trabalhos e objetos na sala de aula, a fim de ampliar o repertório. Foi quando colocamos uma rede, como as de proteção, no teto. No entanto, quando as crianças chegaram na sala de aula, acreditavam que havia passado uma aranha e deixado sua teia, dando vida ao projeto $A$ vida das Aranhas.

Começou a investigação sobre a vida e as espécies das aranhas, com vídeos, imagens, histórias, canções, entre outros. Com isso, as narrativas fantasiosas sobre aranhas imensas e horripilantes vieram à tona, abrindo espaço para a proposta de confecção de uma aranha gigante.

No ano anterior, as crianças haviam visitado o Museu de Arte Moderna (MAM), e lembraram da obra Aranha (Spider), da artista Louise Bourgeois, exposta na marquise. Inicialmente, escolhemos que reproduziríamos a viúva negra. 


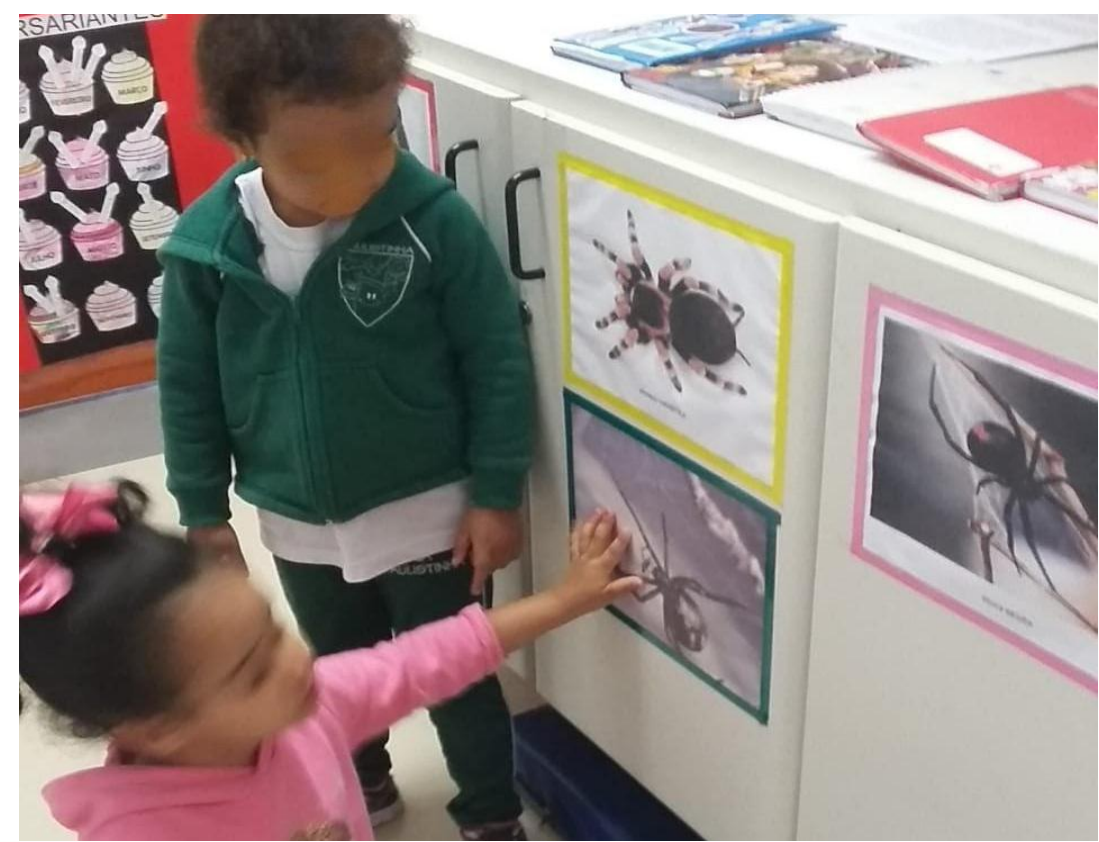

Figura 1: Definição da espécie.

Fonte: acervo pessoal.

Em seguida, definimos que utilizaríamos jornal, cola, tinta guache, bexigas e arames, visto que eram os materiais que tínhamos em mãos e de fácil manuseio para as crianças.

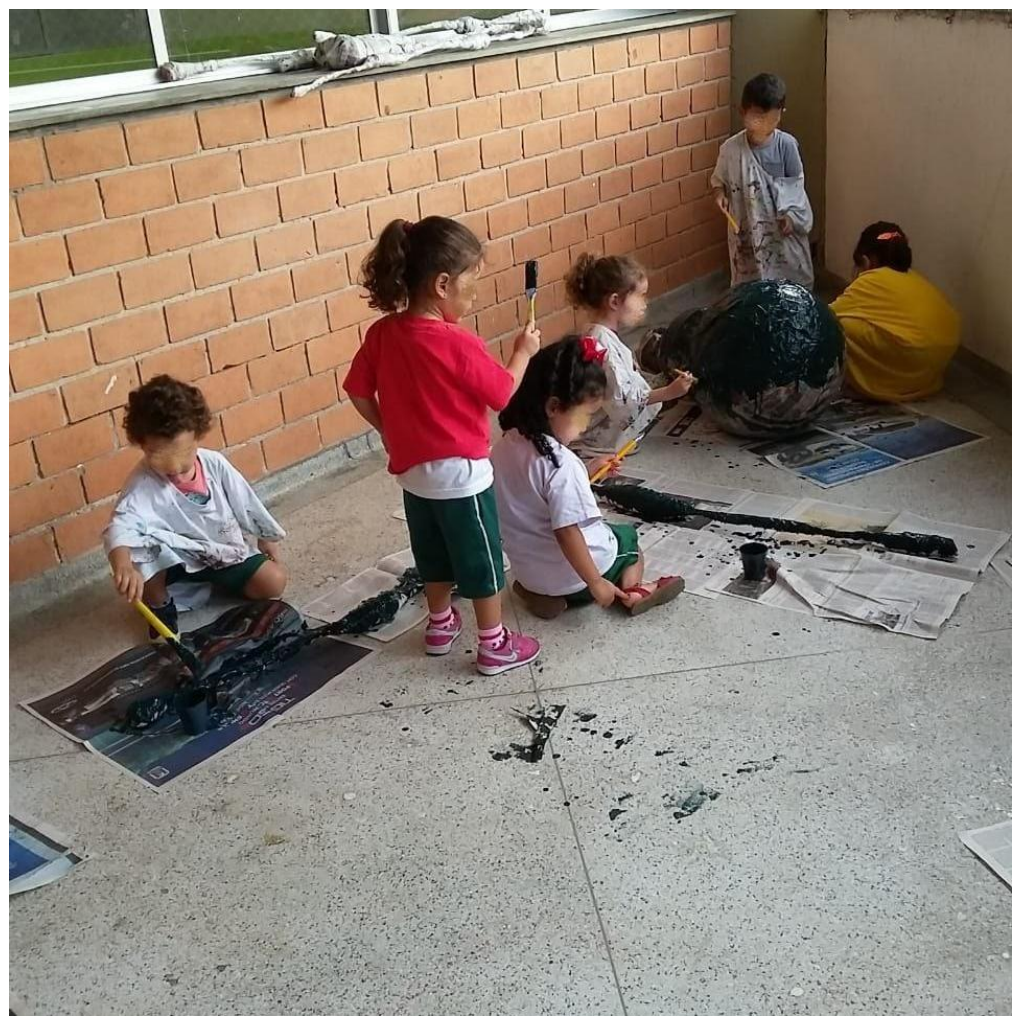

Figura 2: Pintura da aranha.

Fonte: acervo pessoal. 
Após exploração dos materiais, iniciamos a construção da aranha de forma coletiva. O processo de construção foi realizado em diversas etapas, como pintura e colagem. Paralelamente, ocorreram também outros estudos, como desenho de observação e leitura de histórias.

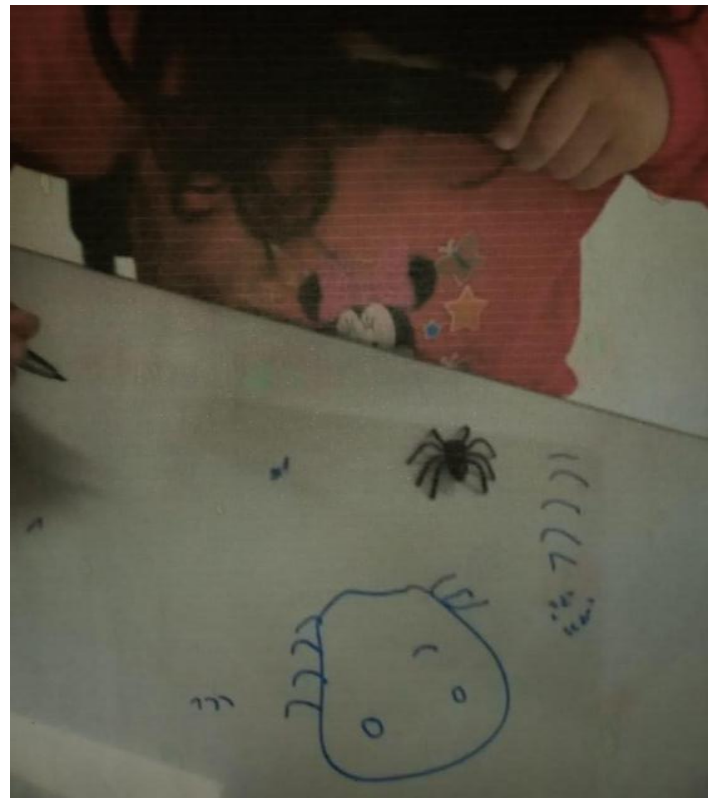

Figura 3: Desenho de observação. Fonte: acervo pessoal.

A definição do local de instalação da aranha não foi feita com as crianças, visto que a única possibilidade era o parque da escola, devido às complexidades estruturais. $\mathrm{Na}$ prática, colocamos elástico em volta da aranha, remetendo às teias.

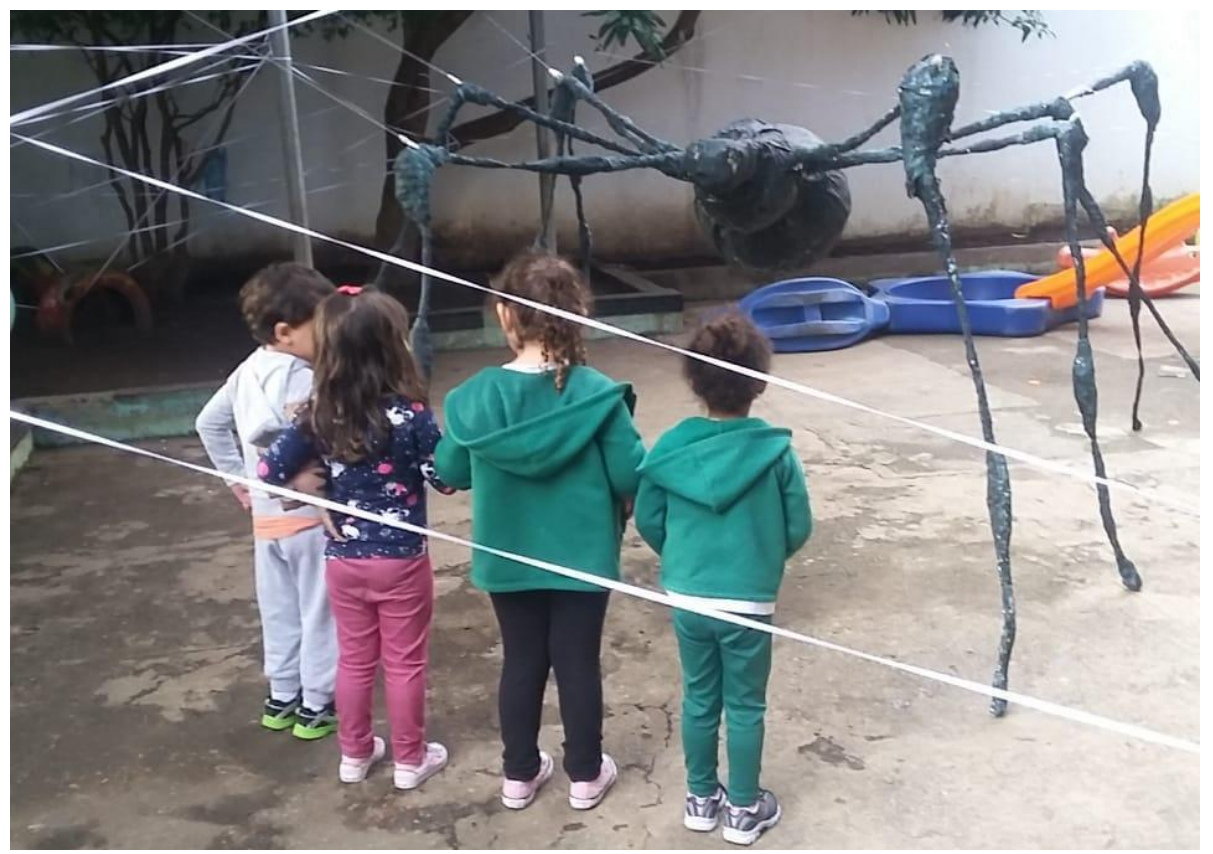

Figura 4: Instalação Aranha.

Fonte: acervo pessoal. 
A instalação, por sua vez, oportunizou vivências lúdicas não só para as crianças da turma do Mundo Encantado, mas também para toda a comunidade escolar, que percorria e descobria os encantamentos do mundo da aranha.

Diante dessa prática, observa-se a presença da instalação direta, isso porque as crianças são as precursoras em todas as etapas. Como vimos, a partir de uma narrativa lúdica, definiu-se o projeto que seria investigado, apresentamos fotos, vídeos, desenhos, histórias, músicas e obras de arte, a fim de repertoriar os educandos. Além disso, integramos as famílias para coleta de materiais, definimos metas durante as rodas de conversa e experimentamos novos materiais expressivos no processo de construção da aranha. Dessa forma, a instalação potencializa o tema investigado, apresenta novas experiências óticas, cheiros e sensações.

Já ao finalizar o semestre daquele ano, novos questionamentos e descobertas estavam por vir. As férias de julho convidavam para novas vivências, aliadas a saudade que as crianças têm umas das outras. Logo, as rodas de conversas giraram em torno das experiências que elas tiveram além dos muros da escola.

Neste caso, como o anterior, o objeto de pesquisa surgiu de forma inusitada, nos pequenos detalhes do dia-a-dia. Ressaltamos a importância da sensibilidade que as professoras e professores precisam desenvolver, pois como já dito, é necessário estar com os sentidos apurados, pois esse diálogo, muitas vezes, não ocorre verbalmente.

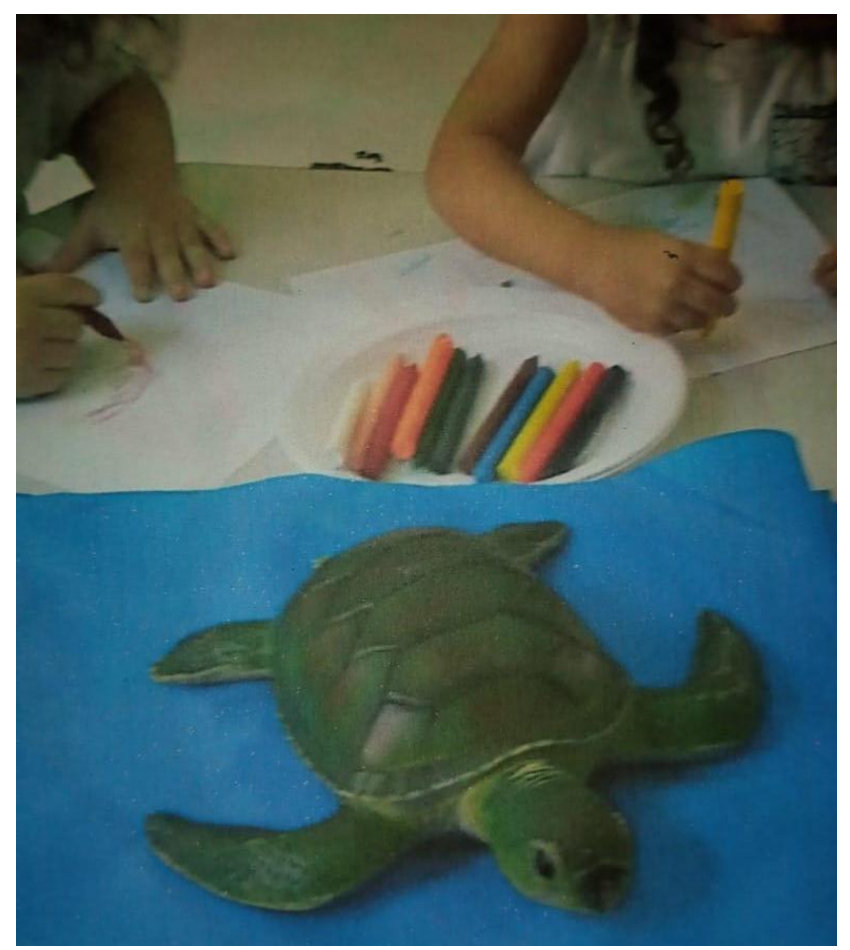

Figura 5: Desenho de observação da tartaruga. Fonte: acervo pessoal. 
Às segundas-feiras eram os dias em que as crianças levavam brinquedos de casa para compartilhar com os colegas, e em um desses dias a professora da turma levou uma tartaruga de pelúcia, que instigou a curiosidade da turma. Nas semanas seguintes, as crianças levaram tartarugas e outros animais, abrindo um novo subprojeto na turma Mundo Encantado, o da Tartaruga.

Como já explicitado, os projetos investigam os interesses que vem à tona, que podem variar, desde o aprofundamento em uma determinada vertente ou na expansão superficial do tema em questão, mas sempre através do repertório e da apresentação de diversos materiais e linguagens, que contribuem para a ampliação do repertório e expressão das crianças e do conhecimento de novos materiais.

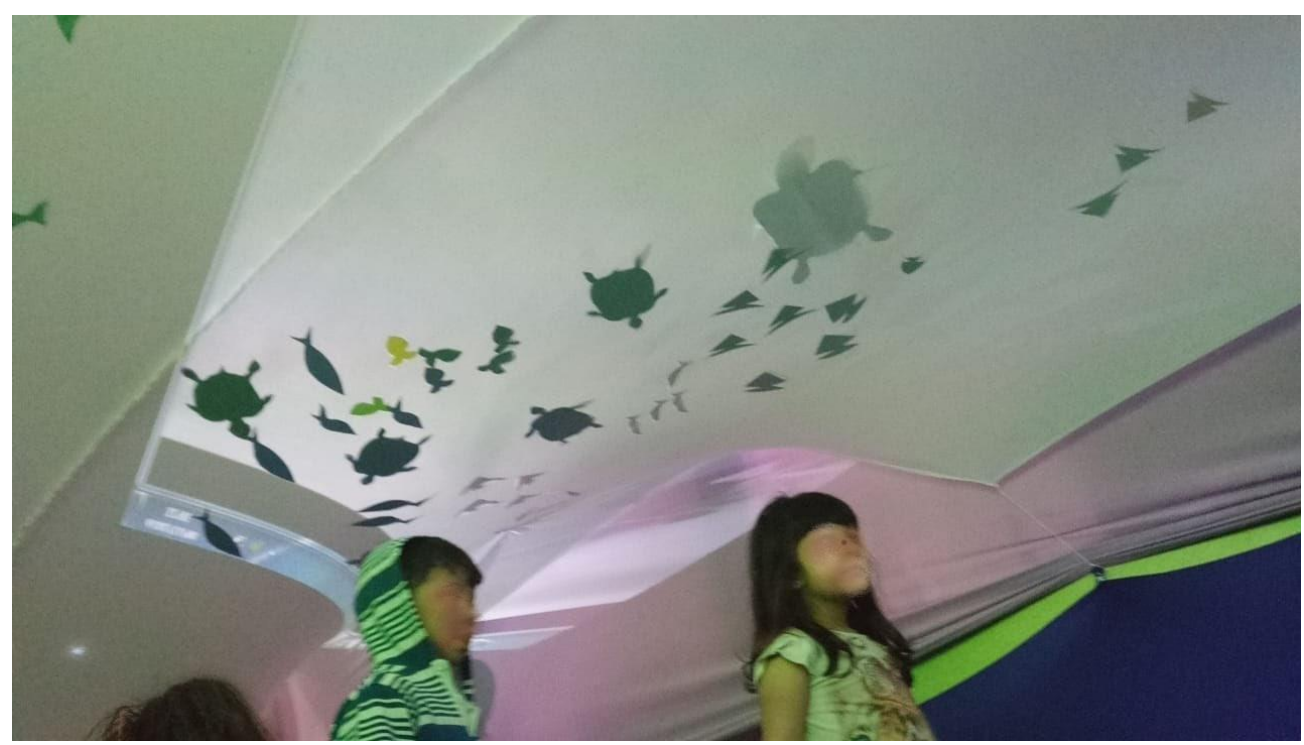

Figura 6: Explorando a instalação Fundo do mar.

Fonte: acervo pessoal.

Pensamos em criar a instalação Fundo do mar, para que as crianças pudessem vivenciar uma experiência lúdica de mergulhadores. Para isso, colocamos dois tecidos um branco e outro azul - dispondo silhuetas de animais marinhos, além de um vídeo com aparição de tartarugas e tubarões, que era lançado sobre o tecido branco acima. Já o tecido azul estava esticado abaixo, proporcionando desequilíbrio ao andar sobre ele. Havia também uma iluminação azulada e sons marinhos, compondo o restante da instalação. 


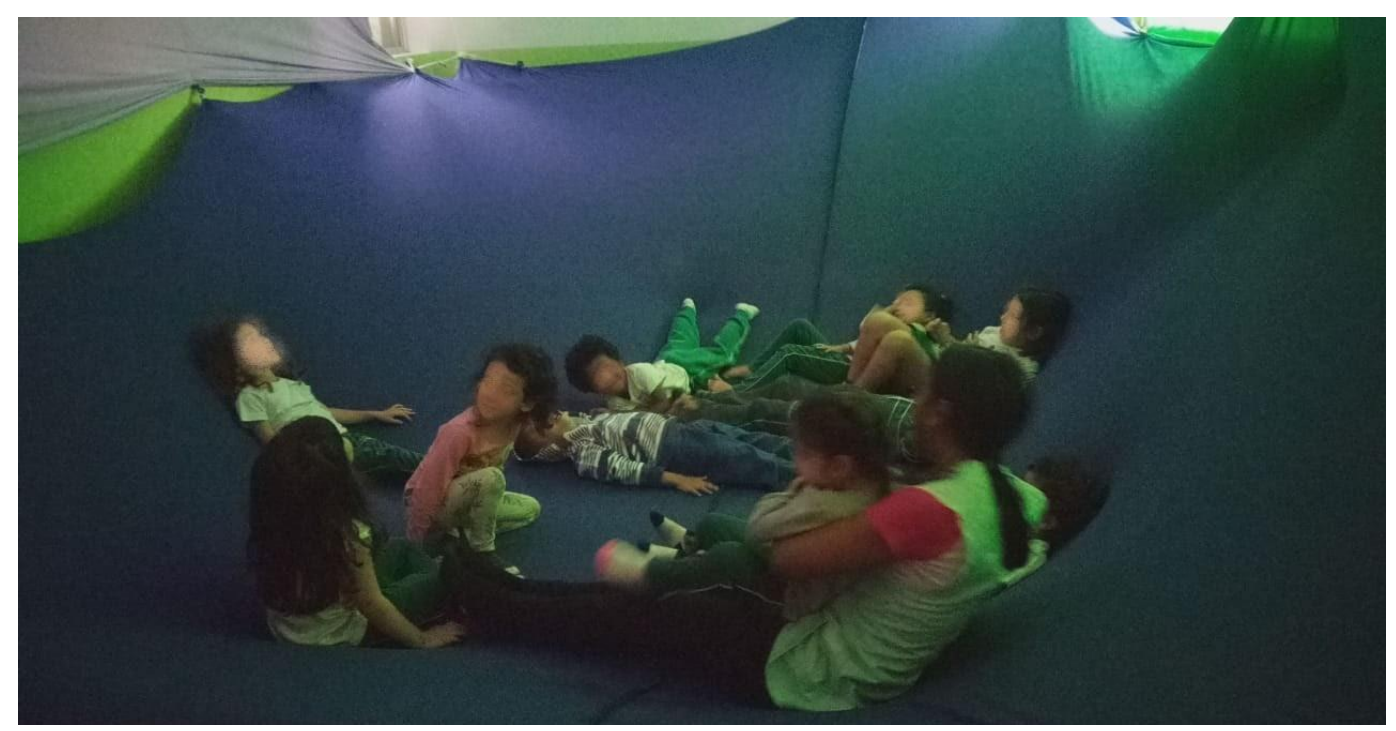

Figura 7: Turma Mundo Encantado na instalação Fundo do mar. Fonte: acervo pessoal.

Como observado, a instalação indireta também foi realizada a partir do projeto de investigação da turma, porém, neste semestre outras turmas estavam pesquisando temas referentes ao fundo do mar. Então, ressaltamos que as crianças são as precursoras dos projetos, nossas ações são realizadas a partir da escuta, preparando um ambiente nutrido para novas descobertas, com uma estética pensada para ampliar repertórios, lúdicos e brincantes, que possibilitam experiências com o corpo inteiro. No entanto, diferente da instalação direta, neste caso não há a participação das crianças no processo de criação, por isso o projeto é caracterizado como instalação artística indireta.

\section{Considerações finais}

$\mathrm{Na}$ arte contemporânea, determinados objetos do cotidiano foram deslocados para museus, galerias, centros culturais e demais ambientes, a partir desse momento, eles ganharam novos sentidos e significados. As instalações na primeira infância, por sua vez, convidavam os educandos à experimentação de novos materiais expressivos, a fim de reutilizá-los, ressignificá-los e transformá-los em algo novo, instigando um fazer inventivo.

A instalação direta e indireta não se limita à educação em arte. Notamos também que contribui na educação do corpo inteiro, entrelaçando as diversas áreas do conhecimento, por não ser pensada de forma fragmentada, e sim integralmente, no âmbito interdisciplinar. Ao deslocar o objeto de estudo para um novo ambiente, a ação contribui para novas leituras, já que este é apresentado a partir de outras perspectivas e linguagens, contribuindo na decodificação e ressignificação por parte das crianças. 
O domínio de uma nova linguagem oferece, à pessoa que a domina uma nova forma de conhecer a realidade, e de transmitir aos demais esse conhecimento. Cada linguagem é absolutamente insubstituível. Todas as linguagens se complementam no mais perfeito e amplo conhecimento real. Isto é, a realidade é mais perfeita e amplamente conhecida através da soma de todas as linguagens capazes de expressá-la (BOAL, 1975, p. 125).

Compreendemos, então, que as instalações, na Educação Infantil, tornam o ambiente um lugar lúdico e potente para experiências com os corpos inteiros, aguçando os sentidos, as múltiplas linguagens e expressões, com estéticas variadas de nossa cultura e de outras. Essa prática permite ampliar o repertório, já que os convida para criar, imaginar e explorar. Por fim, compreendemos que o protagonismo das crianças no processo de criação da instalação direta desenvolve um sujeito crítico e transformador.

\section{Referências}

BOAL, Augusto. Teatro do oprimido e outras poéticas políticas. Rio de Janeiro: Civilização Brasileira, 1975.

BORGES, Camila Bettim. Respingos, colagens, vozes, sensações. In: CUNHA, Susana Rangel. Arte Contemporânea e Educação Infantil: crianças observando, descobrindo e criando, 1.ed. Porto Alegre: Mediação, 2017, p. 65 -73.

BRASIL. Ministério da Educação; Secretaria de Educação Básica. Diretrizes curriculares nacionais para a educação infantil. Brasília: MEC, SEB, 2010.

BRASIL. Ministério da Educação; Secretaria de Educação Básica. Base Nacional Comum Curricular. Brasília: MEC, SEB, 2018.

CUNHA, Susana Rangel Vieira da. Pintando, bordando, rasgando, desenhando e melecando na educação infantil. In: CUNHA, Susana Rangel Vieira da (Org.). Cor, som e movimento: a expressão plástica, musical e dramática no cotidiano da criança. Porto Alegre: Editora Mediação, 1999, p. 7-36.

CUNHA, Susana Rangel Vieira da. Uma arte do nosso tempo para as crianças de hoje. In: CUNHA, Susana Rangel Vieira da; CARVALHO, Rodrigo Saballa de (Orgs.). Arte contemporânea e educação infantil: crianças observando, descobrindo e criando. Porto Alegre: Editora Mediação, 2017, p. 9-26.

DICIONÁRIO, Michaelis. São Paulo: Melhoramentos, 2020. Disponível em: <https://michaelis.uol.com.br/moderno-portugues/busca/portugues-brasileiro/terreiro/> Acesso em: 20 fev. 2021.

FORTUNA, Volnei. A relação teoria e prática na educação em Freire. Revista Brasileira de Ensino Superior, Passo Fundo, v. 1, n. 2, p. 64-72, 2015. Disponível em: <https://seer.imed.edu.br/index.php/REBES/article/view/1056>. Acesso em: 4 jan. 2021.

FREIRE, Paulo. Pedagogia do oprimido. Rio de Janeiro: Paz e Terra, 1974. 
HUIZINGA, Johan. Homo Ludens: O jogo como elemento da cultura. São Paulo: Perspectiva, 2007.

IAVELBERG, Rosa. Arte, infância, formação docente e cultura na escola. In: CUNHA, Susana Rangel Vieira da; CARVALHO, Rodrigo Saballa de (Orgs.). Arte contemporânea e educação infantil: crianças observando, descobrindo e criando. Porto Alegre: Editora Mediação, 2017, p. 27-36.

MAGDALENO, Alessandra Barbosa. Por encanto, contando contos... Histórias de um projeto de trabalho. In: OSTETTO, Esmeralda Luciana (Org.). Encontros e encantamentos na educação infantil: partilhando experiências de estágios. São Paulo: Papirus, 2000, p. 8397.

REGO, Teresa Cristina. Vygotsky: uma perspectiva histórico-cultural da educação. Petropólis: Editora Vozes, 1995.

RICHTER, Sandra. Manchando e narrando: o prazer visual de jogar com cores. In: CUNHA, Susana Rangel Vieira da (Org.). Cor, som e movimento: a expressão plástica, musical e dramática no cotidiano da criança. Porto Alegre: Editora Mediação, 1999, p. 37-55.

RIOS, Sebastião. Cultura popular: práticas e representações. Revista Sociedade e Estado, Brasília, v. 29, n. 3, p. 791-820, 2014. Disponível em: <http://dx.doi.org/10.1590/S0102-69922014000300007> Acesso em: 03 jan. 2021.

SILVA, Luciana Bosco e. Instalação: espaço e tempo. 2012. 240 f. Tese (Doutorado) Universidade Federal de Minas Gerais, Escola de Belas Artes, Belo Horizonte, 2012. Disponível em: <https://docplayer.com.br/7373700-Luciana-bosco-e-silva-instalacaospaco -e-tempo.html>. Acesso em: 05 jan. 2021.

SILVEIRA, Cayenne Ruschel da; VIEIRA, Stéfani. Criando com pedaços de papel. In: CUNHA, Susana Rangel Vieira da; CARVALHO, Rodrigo Saballa de (Orgs.). Arte contemporânea e educação infantil: crianças observando, descobrindo e criando. Porto Alegre: Editora Mediação, 2017, p. 103-110.

SOGABE, Milton. O espaço das instalações: objeto, imagem e público. In: Encontro Nacional da Associação Nacional de Pesquisadores em Artes Plásticas - Panorama da Pesquisa em Artes Visuais, 17., 2008, Florianópolis. Anais eletrônicos. Florianópolis: ANPAP, 2008. Disponível em: <http://anpap.org.br/anais/2008/artigos/180.pdf>. Acesso em: 04 jan. 2021.

VYGOTSKY, Lev Semionovich. Imaginação e criação na infância: ensaio psicológico. São Paulo: Editora Ática, 2009.

\footnotetext{
i Mestrando em Artes da Cena no Célia Helena, Especialista em Contação de História pela Casa Tombada e graduado em Educação Artística. É Artista-educador no Núcleo de Educação Infantil Paulistinha - UNIFESP. Membro do Grupo de pesquisa Respeito das Crianças, Educação Infantil e Estudos da(s) Infância(s) (CRIEI) e do Núcleo de Educação e Estudos da Infância, do Departamento de Ciências Humanas e Educação, ambos da Universidade Federal de São Carlos, campus Sorocaba. Além disso, integra o Grupo de Pesquisa sobre e com bebês, crianças e infâncias - Acriançar, do Núcleo de Educação Infantil Paulistinha - Universidade Federal de São Paulo.
} 
ii Ator, professor e diretor teatral. Doutor (2012) em Artes pela Universidade Estadual de Campinas (Unicamp), na área de Interpretação Teatral, mestre em Artes (2005) e bacharel em Artes Cênicas pela mesma universidade (1996). Atualmente é coordenador de graduação e coordenador geral de pós-graduação lato sensu da Escola Superior de Artes Célia Helena, onde também atua como docente permanente do Programa de Mestrado Profissional em Artes da Cena, tendo colaborado da criação do curso e coordenado o período de implantação. Desde 2010, é professor da mesma instituição no curso de bacharelado em Teatro, onde atua nas disciplinas Jogos e Pedagogia Teatral e Interpretação. É responsável pelo Módulo Fundamentos da Direção e Atuação na "Pósgraduação/Especialização em Direção e Atuação" e orienta trabalhos de conclusão de curso prático-teóricos em pós-graduações lato sensu e em iniciações científicas na graduação. Deu aulas de Teatro, de 2001 a 2004, no Acadêmico-COC/Limeira, para alunos de Educação Infantil, Ensinos Fundamental e Médio. Lecionou em escolas públicas de teatro ligadas ao Projeto Social Vizinho Legal Cultura (2008/2010). Atuou no grupo de pesquisa cênica Boa Companhia, onde trabalhou por mais de 20 anos como ator e gestor, também como iluminador e professor em workshops e cursos ligados a linguagem do grupo; atuou e dirigiu, em parceria com Eduardo Osorio, o espetáculo "Portela, Patrão; Mário, Motorista" (2009), produzido pela Boa Companhia. Atuou no espetáculo "Primus" (1999) por 17 anos. Com a Boa Companhia esteve em diversos Estados do Brasil e no exterior (Cuba, Portugal, Alemanha, Rússia, Inglaterra, Marrocos). Em 2017, dirigiu "Receita para Morrer em Oito dias", com a Companhia Zero Zero. Tem experiência na área de Artes/Teatro, com ênfase em Interpretação e Improvisação Teatral, atuando principalmente nos seguintes temas: improvisação, atuação, espetáculo teatral, e pedagogia teatral.

Como citar esse artigo:

BUTZKE, Ítalo; OTANI, Daves. Instalações artísticas: observar, criar e transformar.

Revista Digital do LAV, Santa Maria: UFSM, v. 14, n. 3, p. 48-66, set./dez. 2021. 